\title{
Increasing the Road Capacity Not Always Improves the Travel Time: A Before and After Study in Tirana
}

\author{
Edison Barhani* \\ *Department of Civil Engineering, Epoka University, Tirana, Albania
}

\begin{abstract}
The rapid growth of the car ownership last two decades in Albania has increased the need for higher transportation capacity. One of the most affected cities in Albania is Tirana where the capacity has not met the demand. Inevitably, the center of Tirana (Skanderbeg Square) plays a crucial part in Tirana Transportation System. After a closure of about 2 years, being under reconstruction planned to be car-free area, Skanderbeg Square opened to traffic in 2011 by motorizing it again. This study analyses performance parameters such as: Travel Time, Waiting Time, and Passenger Movements for bus and passenger cars passing through the Skanderbeg Square before and after it was opened to traffic. Kinostudio-Kombinat bus line has been selected as the only line passing through the center of Tirana. Changing the land use from car-free to motorized one has created a valuable possibility to compare the traditional approach; which focuses only on cost to the sustainable one; which includes the environment and social aspects, too in the evaluation. Wider roads, shorter travel times and higher speed travel at the center (CBD) have made vehicle usage more attractive. At the same time, bus travel times have been improved at the center of Tirana. However, the total travel times were not only enhanced, but at some locations (especially near the CBD) where deteriorated. This study showed that traffic congestion problems are not solved but are shifted to other parts of Tirana Transportation System. In addition, public transportation revealed to be overcrowded, forcing passengers to use other modes like passenger car. Last but not least, other modes like bike or motorcycle riding should be encouraged as alternative to the passenger car.

Keywords: travel time, waiting time, public transportation, pas senger car, sustainable transportation
\end{abstract}

\section{INTRODUCTION}

Traffic congestion in Tirana, one of the fastest growing cities in Europe during the last decades, imposes a high operational penalty on bus services. Collapse of Socialist regime made Albania politically and economically an open country. With very wide roads and a low number of vehicles the roads of Tirana had almost no traffic congestion. However, by the creation of the private sector, Albania in general and Tirana as Albanian Capital city started a very rapid development. Tirana population (city only) doubled approximately every decade and according to Census 2011 it is 536,998 [1]. The same data source revealed that the number of dwellings have increased by $67 \%$ during the last decade. However, $22.6 \%$ of existing dwellings are not inhabitated. To cope with this very fast development, Tirana Municipality has been continuously investing in its transportation systems by constructing now roads, widening the existing roads and maintaining them. According to this concept, the strategy followed by Tirana Municipality to solve the traffic congestion problem has been always to increase the capacity of the transportation system to be able to accommodate this high number of vehicles entering to the traffic. However, struggles to increase the supply have not always led to solution of the congestion problem. Sometimes, a reverse affect has encountered.

In Europe a majority of citizens are calling for changes to promote modes of transport which are more respectful of their environment [2]. According to EC White Paper in 1999, 70 \% of Europeans said that they were now more worried about the quality of the air they breathe than they were in 1994. They put air pollution at the top of their list of environmental concerns and quoted car traffic problems as the main reason for their discontent as far as the environment in which they lived was concerned.

\section{LITERATURE REVIEW} \subsection{The Traditional (Old) Approach to the} Problem

As car ownership and use have increased, in Europe [3] over the past 30 years and in Albania [1] in the last 20 years, the reaction to the pressure created by additional traffic demand has often been to increase the level of supply, in other words provide additional road space. This traditional approach of providing supply to meet demand is no longer always appropriate. There is a growing body of evidence indicating that the benefits of creating additional road capacity are not as significant as it was previously believed. As it is indicated in Fig. 1 
in 2003 Litman indicated that the road widening is not a solution for decreasing the congestion level. However, improving public transport and designing High Occupancy Vehicle (HOV) lanes decrease the congestion level [4].

In extre me cases the provision of new road links may in fact increase congestion problems. This occurs through a process that is known as traffic 'induction'. In 1994, the UK Governmentcommissioned Sactra report [5] provided evidence on the impact of new road building on traffic levels in the area of the scheme. The report revealed that when new road capacity is provided, overall traffic levels in the vicinity of the scheme may actually increase. The evidence does not offer a reliable means of predicting the extent of this traffic increase but case studies suggest that it is typically around 10 $\%$ in the short term, and $20 \%$ in the longer term.

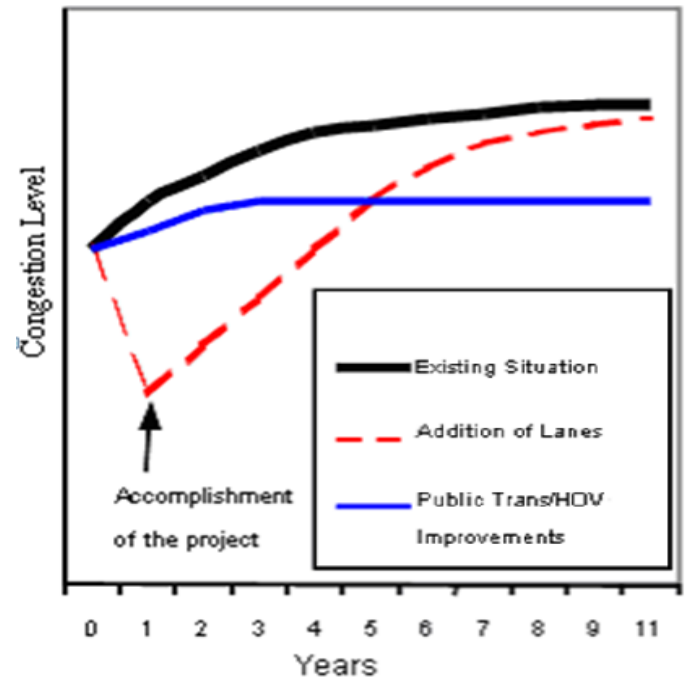

Figure 1. Comparis on of road widening and public transport/HOV (Litman, 2003)

In Tirana and many other large cities all around the world there is additional reason as to why the provision of additional road capacity is problematic for city planners. There is a lack of available space in which to expand these capacities. The provision of supplemental road capacity becomes more critical in very crowded cities like Tirana, where this provision is very much restricted by build ings.

\subsection{The Traditional (Old) Approach to the Problem}

Sustainable transport as defined by the Brundtland Commission [2], is "development that meets the needs of the present without compromising the ability of future generations to meet their own needs", then sustainable transport should be the use of transport and other factors in helping to meet present needs without jeopardizing future generations.
As it is shown in the Fig. 2 the three criteria that any element of sustainable transport should satisfy are; environmentally sensible, society fair, and economically sound. First of all, the sustainable transportation system has to be environmentally sensible. It has to integrate environmental concerns into transport policy making. Secondly, the sustainable transportation system has to be economically sound. What is good economically is almost always good environmentally, as long as the economic system is working to accurate prices and not subject to distortions from hidden subsidies. And the reverse is true; an economically sound approach to pricing and investment can deliver enormous benefits for the environment. Last but not least, transport can only be sustainable if it is fair on all members of society, in other words, if it provides a minimum level of access to basic services for all people. These three criteria may sound as ambitious as they seem incompatible. But in fact they complement each other.

The concerns that arise from the increased demand for transportation, made transport a crucial issue in many European metropolitan cities [2] and therefore for Tirana, too. The actual transportation system in Tirana does not take into account the fundamentals of the sustainability. Therefore, the need for a detailed and comprehensive transport policy, to encourage sustainable transport and sustainable mobility, is es sential and crucial.

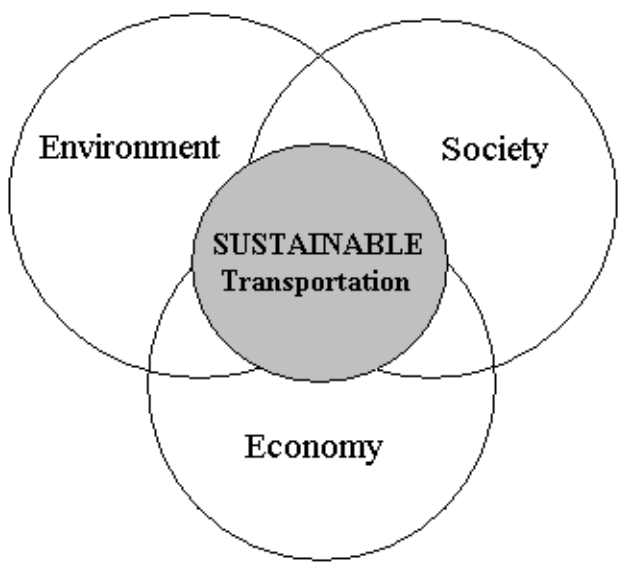

Figure 2. The criteria of Sustainable Transportation

The principal challenge for most European cities and also for Tirana is to find ways of using the existing road capacity more efficiently. While it is obvious that provision for car-based mobility will continue to be an essential part of traffic management planning, searching and finding ways to encourage more use of alternative modes of transport (public transport, cycling and walking) is the goal of any sustainable urban policy. Where road space is restricted, providing adequate space for these alternative modes may require a reallocation of 
highway capacity. When the roads under consideration are already highly congested, it is typically assumed that reducing the capacity available for cars will result in increased traffic congestion in the surrounding streets. However, as the evidence in the previous applications this is not necessarily the case. Some pioneering cities as reported by Gehl and Gemzøe, for example Copenhagen in Denmark, have adopted such a policy for many years with great success [6].

The greatest challenge is presented in cities or areas of cities where road conditions are already congested, in particular during peak times. In these cases the only way to provide more space for more sustainable modes of transport is to take road space from private cars, either on a permanent 24 -hour or on a temporary 'shift' basis. Taking capacity away fro $m$ the dominant road user (i.e. the private car) is a brave decision for an authority to take. Logic suggests that if a network is already congested, the removal of capacity can only exacerbate the situation. However like Copenhagen in Denmark some other cities such as Kajaani in Fin land (1996), Wolverhampton in England (1986), Vauxhall Cross - London in England (2001), Nuremberg in Germany (1994), Strasbourg in France (1992), Ghent in Belgium (1997), Cambridge (1997), and Oxford (1999) in England are living proofs for the benefits of sustainable transport approach (European Commission, 2004). Many of these cities continued with road space rearrangement schemes despite the traffic chaos that would result. However, the initial problems of traffic congestion had short life and after an adaptation period a portion of the traffic was reduced.

Vuchic in 1999 [7] cited "Citizens make travel choices based on their individual needs, but a comprehensive plan must be in place to coordinate these individual choices into an efficient transportation system." In other words, rather than focusing on solving transportation problems in specific locations it is better to perform comprehensive studies for Tirana as a whole.

There is a growing body of evidence that where well-planned measures to reduce road space for private cars are implemented in congested areas and where no alternative network capacity is available, over the long term the predicted traffic chaos does not occur. The experience in a number of European cities is that [8]:

- Traffic problems following the implementation of a scheme are usually far less serious than predicted,

- After an initial period of adjustment, some of the traffic that was previously found in the vicinity of the scheme 'disappears' or 'evaporates', due to drivers changing their travel behavior,
- As a result the urban environment becomes more livable in many respects.

In addition, there are many innovations and transport management strategies and initiatives that can be regarded to achieve more sustainable transportation system. Litman in 22016 listed some of them as below [9]:

- Parking management strategies,

- Public transport initiatives,

- Walking and bicycling initiatives,

- Smart growth strategies and initiatives.

\section{STUDY AREA AND ROUTE}

The purpose of this study was to compare different parameters like travel time, speed, passenger boarding and alignment, stop time for buses and passenger cars (PC) before Skanderbeg Square was opened and after its opening to traffic. Skanderbeg square is Tirana's most important square, where most of the governmental buildings, national museum and historic buildings are located around. This center has been under construction for more than two years in accordance with the plan where it was planned to be a fully pedestrianized and a car-free square. However, this plan was suddenly changed in 2011, making this square again motorized. The center has again currently been closed and constructions to turn it to a pedestrianis ed area has started. However, the current situation is not a scope of this research.

Bus route from Kombinat to Kinostudio (Fig. 3) was considered to be a representative route for other routs that pass through this center. The length of this route from Kombinat to Kinostudio (East Direction) was $8,739 \mathrm{~m}$ before and 8,440 after the opening of the square and comprised 17 bus stations. On the other hand, West Direction, from Kinostudio to Kombinat has 16 stations but its length changed from $8,052 \mathrm{~m}$ to $7,974 \mathrm{~m}$ after the opening. The roads that the buses travel vary from arterials to collectors and from two to six lanes, with and without street parking. They travel through commercial, industrial, residential, and through the Skanderbeg Square.

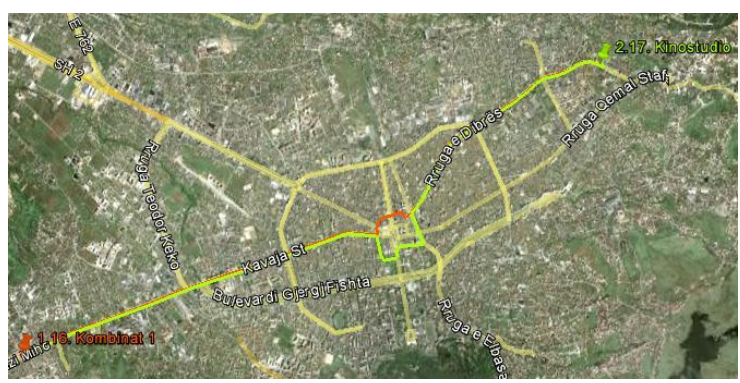

Figure 3. Study area; Ko mbinat-Kinostudio bus route 
Bus Routes before and after the opening of Skanderbeg Square are depicted in Figure 4. The inner shaded area shows the area which was closed being under construction. During this time the movement of traffic was in the outer ring for both directions. As a result, the outer shaded area was non-motorized. Congestion level in the outer ring has been very high and thus affecting the movement of buses and other vehicles especially during the peak hours. After the opening of square, since there were more travel options and more capacity available through the center, traffic congestion has been lighter.

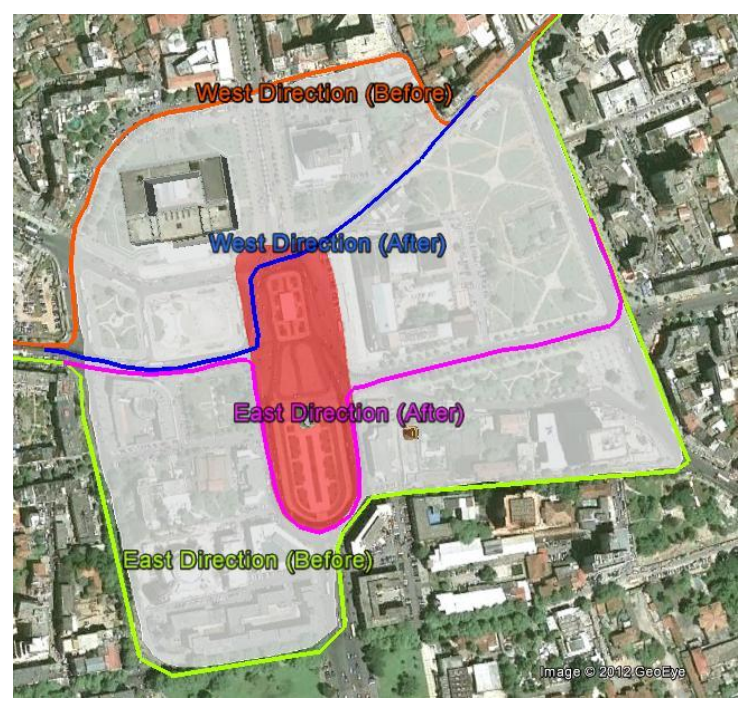

Figure 4. Skanderbeg Square and traffic movement before and after the square opening.

\section{DATA COLLECTION}

Teams of two people collected data by driving buses during randomly selected times of the day starting from 7:00 till 19:00. Bus operation characteristics; travel times, stop time in the bus station, boarding and alignment of passengers' information were collected manually for each direction at each bus station. Distance from each station was calculated from physical maps. On the other hand, another team drove a passenger car to collect the same information to be able to compare with the bus one.

All the data were collected within three days from Tuesday to Thursday and the weather was cloudy. The same study was conducted three years from the opening of the Skanderbeg Square. To avoid any bias, the "after opening" study was conducted again within three days from Tuesday to Thursday where the weather conditions were the same and traffic characteristics were adjusted.

\section{ANALYS IS}

The collected information was processed and presented as travel speed of each analyzed mode before and after the opening of the Skanderbeg square. Travel speed for passenger cars (PC) and Bus before and after the opening of the square has been presented in Fig. 5 below. Distinguishably travel speeds increase moving outward from the center (from $10 \mathrm{~km} / \mathrm{h}$ to $30 \mathrm{~km} / \mathrm{h}$ ).

Travel speed of PC within the CBD was observed to be improved by $21 \%(2.8 \mathrm{~km} / \mathrm{h})$ while for bus was higher; about $31 \%(3.4 \mathrm{~km} / \mathrm{h})$. So, the increase of capacity in the center has improved the travel speed within the square. On the other hand, the travel speed within the Inner Ring (adjacent to the CBD) showed deterioration. Travel speeds of PCs were observed to decrease by $10 \%$ while bus travel was observed to slow down by $7 \%$. In other words, the capacity of the roads in the vicinity of the square is not enough to handle the high number of vehicles traveling within the square. As a result, higher delays and slower speeds have deteriorated traffic congestion in the vicinity of the square.

The same trend was observed within Outer Ring and Suburban. The total travel speed of each mode from the starting point to the end point was observed to be almost not changed (less than $0.5 \%$ ). In other words, improvements in the center of Tirana were not reflected to the total travel. In contrast, the increased friction toward the center (within Inner Ring) shifted the problem from the center to Inner Ring.

Moreover, this significant change in travel speeds, directly affect traffic light signalization timing which need to be re-optimized. Furthermore, parking demand is expected to have been increased in the vicinity of the $\mathrm{CBD}$, hence slowing down the traffic flow by increasing flow friction. Information from municipality of Tirana shows that there are underground parking constructions currently going on and planned ones in the perimeter of CBD.

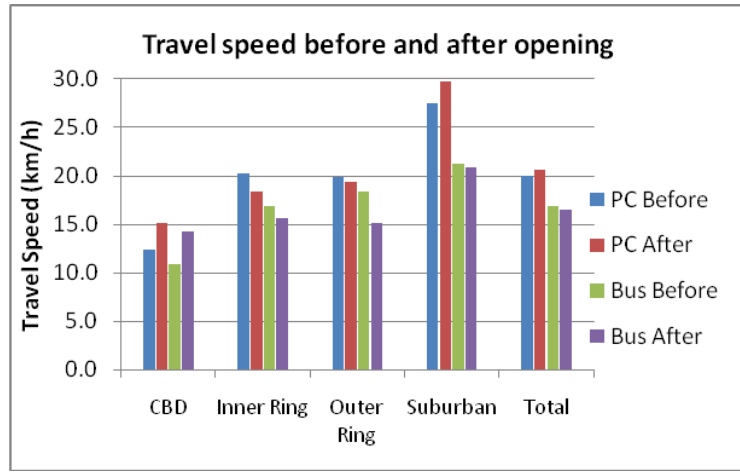

Figure 5. Travel speed of each mode before and after the opening

The total travel and stop times of the bus mode are shown in Figure 7 below. Interestingly, total travel time in east direction is improved while in west direction is deteriorated. The information in 
the west direction was found to be misleading until a further detailed analysis for each bus stop was investigated. In the end, it was found out that, busses in the west direction averagely stopped for longer time (about 5 minutes) than usual at Bank station. In other words, this station serves as terminal station. On the other hand, an increase in both directions of stop time for has been observed.

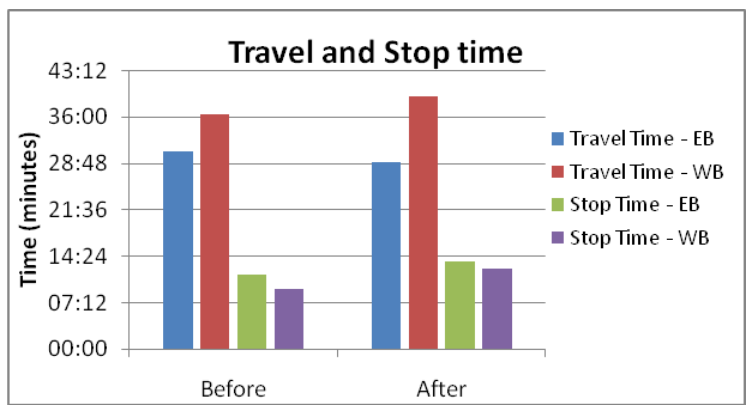

Figure 6. Travel and stop time of bus mode

Fig. 7 shows average passenger accumulation per trip. The maximum accumulation of 80 passengers is reached at Bank bus station, for the west direction. On the other hand, the maximum accumulation of 82 passengers is reached at 21 Dhjetori bus station for the east direction. It should be noted that the number of the passengers in the east direction has been increased for the east direction from 60 to 82 .

The bell shape of the distribution shows that most of the passengers come into the Square for different purposes from both directions. As a result of this type of distribution bus stations near the square serve as terminal stations. Adding another line from Medresea to Shkolla Teknologjike would have improved the comfort of public transportation mode, thus making it more attractive.

In addition, the maximu mu mber of passengers at the same time in the bus has been measured to be 82 . This standard type bus is designed to carry about 60-65 passengers. This high number of passengers above the bus capacity shows that a lot of people are using the bus mode. However, the supply seems still to be low compared to the demand by either bigger or more frequent buses, making this mode less comfortable.

Moreover, the longest waiting time is observed in Bank station; apparently showing that this station is used as a terminal station or for schedule adjusting purposes. This situation discourages bus users.

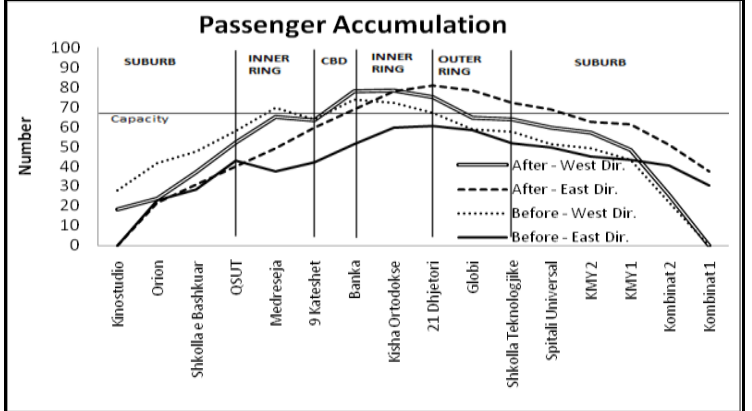

Figure 7. Pas senger Accumulation

However, travel speed in the sections entering and exiting the square has been decreased in the entrace and exit by $3 \mathrm{~km} / \mathrm{h}$ and $2 \mathrm{~km} / \mathrm{h}$ respectively, for east direction. At the same time, travel speed at entrance of the squre has been decreased by $2 \mathrm{~km} / \mathrm{h}$ and at the exit by $4 \mathrm{~km} / \mathrm{h}$. In other words, this the capacity of the roads in the vicinity of the square is not enough to handle the high number of vehicles traveleing within the square. As a result, higher delays and slower speeds has deteriorated traffic congestion in the vicinity of the square.

\section{CONCLUSIONS AND RECOMMENDATIONS}

This study showed very significant conclusion that should be paid attention to for a better transportation system in Tirana. Benefits of creating additional road capacity are not as significant as it was previously believed, (Litman, 2003). The road widening is not a solution for decreasing the congestion level. However, improving public transport and/or encouraging other modes of transport like biking decrease the congestion level.

The increase of road capacity in the center has improved the travel speed within the square. However, travel speeds in the sections entering and exiting the square has been decreased for both directions. This situation was observed before and after the opening of the square. As a result, higher delays and slower speeds have deteriorated traffic congestion in the vicinity of the square.

The longest waiting time is observed in Bank station; apparently showing that this station is used as a terminal station or for schedule adjusting purposes. This situation discourages bus users.

A very high number of passengers exceeding the bus capacity were observed during this study. This shows that even though people are using bus mode caring capacities of the line was not increased. This discourages passengers to use other modes of transportation like passenger cars minibuses. 
The author predicts that the biggest impact to the transportation system occurs during the rainy weather. So, further investigations should be performed under bad weather condition to compare the size of the affect.

Bike and motorcycle ridership need to be further investigated for their benefits, which later might be used as a guidance for decision makers.

\section{REFERENCES}

[1] Albanian Institute of Statistics, www.instat.gov.al, last visited on December 25th, 2016.

[2] Commission of the European Communities, White Paper, European transport policy for 2010: time to decide, Brussels, 2001

[3] Eurostat, Transport statistics at regional level, ec.europa.eu, last visited on December $20^{\text {th }}, 2016$.

[4] T. Litman, Congestion Reduction Strategies, Victoria Transport Policy Institute, 2003

[5] M. Humphreys, Sustainability in European Transport Policy, European Federation for Transport and the Environ ment, 1994

[6] J. Gehl and L.Gemzøe, Public Spaces, Public Life, Copenhagen: The Danish Architectural Press, 2004

[7] Vuchic R. V., Urban Transit Operations, Planning and Economics, John Wiley \& Sons, 2005

[8] S. Carins, et al. Traffic Impact of Highway Capacity Reduction; Assessment of the Evidence, Londor Publishing, London, UK, 1998

[9] T. Litman, Parking Management Strategies, Evaluation and Planning, Victoria Transport Policy Institute, 2016

[10] E. C. McKnight, S. H. Levinson, K. Ozbay, C. Kamga, E. R. Paaswell, The Impact of Traffic Congestion on Bus Travel Time in Northern New Jersey, 2004

[11] L. R. Bertini, and M. A. El-Geneidy, Modeling Transit Trip Time Using Archived Bus Dispatch System Data, 2002

[12] R. Buehler, and J. Pucher, Sustainable Transport in Freiburg: Lessons from Germany's Environmental Capital, International Journal of Sustainable Transportation, 5:43-70, 2011

[13] M. El-Geneidy A, Hourdos J., Horn ing J., Bus Transit Service Planning and Operations in a Competitive Environment, Journal of Public Transportation, Vol. 12, No. 3, 2009 